УДК 338

\title{
РЕАЛИЗАЦИЯ ИНВЕСТИЦИОННОЙ СТРАТЕГИИ НА ПРЕДПРИЯТИЯХ ПРОМЫШЛЕННОГО КОМПЛЕКСА
}

\author{
Булавко Ольга Александровна \\ д.э.Н., доцент \\ Волков Кирилл Андреевич \\ Волкова Виктория Викторовна \\ ФГБОУ ВО «Самарский государственный \\ экономический университет»
}

\begin{abstract}
Аннотация: В статье рассматривается реализация инвестиционной стратегии и возможности направлений экономического развития в процессе распределения инвестиционных ресурсов, анализируется концепция формирования инвестиционной политики в отраслях промышленного комплекса. Показана необходимость государственного регулирования в процессе распределения инвестиционных ресурсов.

Ключевые слова: Инвестиционная деятельность, инвестиционная стратегия, источники финансирования, инвестиционная политика, промышленные предприятия.
\end{abstract}

\section{IMPLEMENTATION OF AN INVESTMENT STRATEGY AT INDUSTRIAL ENTERPRISES}

\section{Bulavko Olga Alexandrovna Volkov Kirill Andreevich Volkova Victoria Viktorovna}

\begin{abstract}
The article examines the implementation of an investment strategy and the possibilities of economic development directions in the process of allocating investment resources, analyzes the concept of forming an investment policy in the industries of the industrial complex. The necessity of state regulation in the process of distribution of investment resources is shown.
\end{abstract}




\section{СОВРЕМЕННЫЕ СОЦИАЛЬНО-ЭКОНОМИЧЕСКИЕ ПРОЦЕССЫ: ПРОБЛЕМЫ, ТЕНДЕНЦИИ, ПЕРСПЕКТИВЫ}

Key words: Investment activity, investment strategy, sources of financing, investment policy, industrial enterprises.

В современных условиях хозяйствования и развития цифровой экономики реализация эффективной инвестиционной стратегии на предприятиях промышленного комплекса является первоочередной задачей. Именно государство должно стимулировать инвестиционную деятельность промышленных предприятий путем создания благоприятного инвестиционного климата, под воздействием экономических рычагов и формировании новых экономических механизмов. «Государство при проведении промышленно-инвестиционной политики должно придерживаться приоритетов, обеспечивающих достижение устойчивого развития и поддержания темпов роста ВВП путем инвестиционного регулирования». [1, c. 14].

На протяжении последних десятилетий отрасли промышленного производства сталкиваются с ограничением инвестиционных ресурсов. Вышеизложенную проблему способен решить инструмент взаимодействия между экономической системой общества, государственным регулированием и инвестиционной деятельностью промышленных предприятий. $\mathrm{B}$ инвестиционной деятельности промышленных предприятий преобладают инвестиции за счет собственных источников финансирования предприятий (прибыли, амортизации). Государство должно проводить целенаправленную политику по созданию благоприятного инвестиционного климата в стране основы формирования инвестиционной привлекательности отраслей промышленности. Главная цель инвестиционной политики в условиях развития цифровой экономики и реализации Национальных проектов определение основных направлений и механизмов, необходимых для реализации инвестиционной стратегии и эффективного развития промышленного производства. В настоящее время от инвестиций зависит рост ВВП, повышение конкурентоспособности отечественного производства на внутреннем и мировом рынках. В современных условиях инвестиции - это инструмент реализации промышленно-инвестиционной политики, позволяющей обеспечить эффективное развитие отраслей реального сектора экономики, модернизацию промышленности в рамках сценария инвестиционного и инновационного развития. Инвестиционная стратегия 
представляет собой рассмотрение стратегических задач инвестирования, решение ситуационных задач, направленных на реализацию системного подхода при рассмотрении различных факторов, влияющих на процесс стратегического управления на предприятиях промышленного сектора. Эффективная реализация инвестиционной стратегии тесно связана с инвестиционными рисками. В образовании настоящее время людям наиболее систем распространенными методами working количественной нормативному оценки таблица рисков структура являются:

1. статистический директоров метод;

2. основных аналитические методы;

3. оптимизация анализ имеющих финансовой устойчивости общий предприятия и чистый оценка его платежеспособности.

К началу 2021 года ситуация с инвестициями в основной капитал складывается следующим образом:

1. Сокращение роста объемов инвестиций,

2. Снижение роли бюджета в источниках финансирования инвестиций;

3. Увеличение доли собственных средств предприятий, как основного источника финансирования инвестиций в основной капитал.

Однако, оправившись от самой проблемной фазы кризиса в период пандемии, крупные корпорации вернулись к довольно масштабным инвестиционным планам.

Главными направлениями остаются нефтегазовый сектор, энергетика, транспорт. На эти сектора приходится почти три четверти всех намеченных на 2021 год капитальных вложений. Для устранения выявленных дисбалансов следует развивать механизм регулирования инвестиционной, поскольку в рамках действующих механизмов увеличение финансирования инвестиционных проектов, научных исследований и разработок не дает ожидаемого результата, и будет снижаться эффективность промышленного производства. Неэффективная инвестиционная стратегия приводит к следующим негативным последствиям:

- ухудшение финансового положения;

- недостаток собственных финансовых средств;

- неопределенность перспектив развития рынков сбыта;

- трудность привлечения заемных средств;

- недостаточность государственной поддержки инноваций; 


\section{СОВРЕМЕННЫЕ СОЦИАЛЬНО-ЭКОНОМИЧЕСКИЕ ПРОЦЕССЫ: ПРОБЛЕМЫ, ТЕНДЕНЦИИ, ПЕРСПЕКТИВЫ}

- сокращение закупок государством инновационной продукции.

Таким образом, кризисная ситуация на многих промышленных предприятиях в условиях пандемии привела к следующим факторам:

- превалирование инновационной активности в сегменте крупных компаний вследствие отказа от реализации инновационных проектов небольших по масштабам компаний;

- расширение доступа крупных компаний к государственной поддержке независимо от их инновационной активности [2, с. 176].

К числу позитивных, можно отнести следующие факторы:

1. Повышение мотиваций для бизнеса к внедрению энерго- и ресурсоэффективных технологий в условиях ужесточения финансовых ограничений.

2. Изменение структуры спроса на продукцию предприятий в пользу новой, усовершенствованной продукции.

3. Новые возможности для инновационно-активных предприятий, предприятий с существенной долей новой продукции; эти преимущества связаны, прежде всего, с уходом с рынка неэффективных конкурентов.

Для реализации основных направлений инвестиционной стратегии можно выделить следующие направления.

1. Снижение неопределенности по перспективам развития, повышение стабильности регулирования экономической деятельности:

- повышение предсказуемости условий хозяйственной деятельности (в первую очередь предсказуемость тарифной и налоговой политики);

- активизация деятельности государственных институтов по поддержке прямых инвестиций, особенно инновационных проектов.

2. Сохранение позитивных эффектов для инновационно-активных и вертикально-интегрированных компаний с существенной долей новой продукции:

- усиление качественных требований к самим компаниям (скорость обновления оборудования, доля затрат на НИОКР) при предоставлении государственной поддержки;

- установление государством более высоких требований к новым свойствам, качеству продукции при закупках для государственных нужд. 
3. Сохранение и усиление мотиваций компаний к внедрению ресурсои энергоэффективных технологий.

Существующие в настоящее время мотивации для отраслей промышленного комплекса, при улучшении финансового положения, могут несколько снизиться. Поэтому важным представляется в ближней перспективе реализовывать государственные меры поощрительного характера, ориентируясь в отдаленной перспективе дополнить их рыночными механизмами принуждения к модернизации (увеличение налоговых ставок на ресурсоемкое оборудование, запреты на применение отдельных ресурсоемких технологий, усиление требований регламентов и стандартов, введение ограничений по характеристикам товаров для госзакупок).

Наиболее привычные инструменты стимулирования инноваций, связанные с прямым бюджетным финансированием (госзакупки, Федеральные целевые программы, субсидии и льготы) оказывают позитивное воздействие, прежде всего, на инновационную деятельность в крупном бизнесе, который имеет лучший доступ к этим формам поддержки инноваций [3, с. 272]. Привлекательность такой политики для государства определяется более широкими возможностями реализации цифровой экономики, Национальных проектов, инвестиционной и промышленной политики.

\section{Список литературы}

1. Булавко О.А., Иванкина М.С., Туктарова Л.Р., Нургалиева Э.М. Основные аспекты развития промышленной политики. Вестник Самарского муниципального института управления. - 2019.-№ 2.- С. 21-29.

2. Маховикова, Г.А.; Кантор, В.Е. Инвестиционный процесс на предприятии; СПб: Питер - Москва. - 2018. - С. 176.

3. Мыльник В. В. Инвестиционный менеджмент; Академический Проект, Деловая книга - Москва.- 2019. - С. 272. 